\title{
STRATEGI PENERJEMAHAN NAMA DIRI DALAM AMERICAN INDIAN MYTHOLOGY
}

\author{
Andy Bayu Nugroho \\ Prodi Bahasa dan Sastra Inggris, Fakultas Bahasa dan Seni \\ Universitas Negeri Yogyakarta \\ abenugroho_uny@yahoo.com
}

\begin{abstract}
ABSTRAK
Penelitian ini bertujuan untuk mengidentifikasi strategi penerjemahan yang digunakan oleh mahasiswa dalam kasus penerjemahan nama diri yang terdapat dalam American Indian Mythology, dan mengidentifikasi faktor-faktor yang mempengaruhi mahasiswa tersebut menggunakan strategi dimaksud. Penelitian ini diharapkan dapat memberikan kontribusi terhadap pengetahuan mahasiswa dalam hal penelitian penerjemahan yang berbasis pada proses. Metode yang digunakan adalah metode kualitatif yang mendeskripsikan fenomena dalam proses penerjemahan nama diri oleh mahasiswa. Sumber data berupa buku American Indian Mythology yang ditulis oleh Evelyn Wolfson dan diterbitkan oleh by Enslow Publisher, serta terjemahannya yang dikerjakan oleh para mahasiswa Prodi Bahasa dan Sastar Inggris Fakultas Bahasa dan Seni, Universitas Negeri Yogyakarta. Sumber data kedua berupa informasi dari para penerjemah yang didapatkan melalui wawancara untuk mengungkap faktor-faktor yang mempengaruhi mahasiswa dalam pengambilan keputusan untuk menggunakan strategi tertentu. Hasil dari penelitian ini adalah bahwa penerjemah menggunakan beberapa strategi, yaitu copy (91 data), rendetion (43), addition (5), deletion (4), conventionality (3), transposition (1), dancombination of copy, addition dan rendition (1). Copy menjadi teknik yang paling banyak dipilih diikuti dengan rendition. Pertimbangan makna menjadi salah satu faktor penentu pemilihan strategi, antara lain makna semantik, semiotik, dan simbolik.
\end{abstract}

Kata kunci: Strategi Penerjemahan, Nama Diri, Proses Penerjemahan, Penelitian Berbasis Proses

\section{TRANSLATION STRATEGIES OF THE PROPER NOUNS IN AMERICAN INDIAN MYTHOLOGY}

\begin{abstract}
The aims of this research are to identify the strategies applied by the students in translating proper nouns found in American Indian Mythology, and to identify the motivating factors of the students' choosing the strategies. This research is expected to give contribitions to students' knowledge on process-based translation research. This research uses qialitative approach describing phenomena in the translation of proper nouns by students. The data sources are the book American Indian Mythology written by Evelyn Wolfson published by Enslow Publisher and its translation by the students of the English Language and Literature Study Program of the Faculty of Languages and Arts of the State University of Yogyakarta. The second source of the data is information from the translators through interview which uncovers the motivating factors of applying certain strategies. The result shows that the startegies applied by the translators are: copy (91 data), rendetion (43), addition (5), deletion (4), conventionality (3), transposition (1), and combination of copy, addition and rendition (1). Copy becomes the most frequently used technique followed with rendition. Other strategies are less used. Meaning consideration becomes the main factor that motivates the translators applying certain strategies. The meaning includes semantic, semiotic and sound symbolic meanings.
\end{abstract}

Key words: Translation strategy, Proper nouns, translation proses, process-based translation research 


\section{PENDAHULUAN}

Sering muncul pendapat bahwa nama tokoh yang ada dalam suatu cerita tidak perlu dialihkan menjadi nama lain yang spesifik dalam bahasa sasaran, atau setidaknya penerjemah memilih untuk tetap menggunakan nama tokoh tersebut seperti yang ada dalam karya aslinya. Sebagai contoh, nama-nama dalam novel Harry Potter tetap digunakan apa adanya dalam teks terjemahannya. Nama-nama tokoh dalam drama karya Shakespeare juga begitu terkenal karena tetap digunakan dalam beberapa karya terjemahannya.

Namun, dalam beberapa cerita untuk anak-anak, komik Disney misalnya, banyak tokoh yang telah mengalami perubahan nama. Sebut saja Kwik, Kwek dan Kwak keponakan Donal Bebek, Paman Gober, Gufi, Untung, dan lain sebagainya. Hal ini tidak hanya terjadi di Indonesia. Cerita terkenal Alice in Wonderland telah diterjemahkan ke dalam berbagai bahasa. Terjemahan Bahasa Indonesianya saja konon ada lima versi. Christiane Nord (2003) menyebutkan bahwa nama Alice dalam bahasa Spanyol mengalami perubahan menjadi Alicia. Tokoh lain seperti Dinah berubah menjadi Dina, Suse, dan Mimi dalam versi terjemahan berbagai bahasa. Tokoh Mabel dalam versi Brasil justru menjadi Elisa. Tidak hanya nama tokoh, nama tempat pun bisa jadi berubah, terutama apabila cerita tersebut mengalami adaptasi yang cukup signifikan. Nama tempat seperti Australia dan New Zealand dalam cerita yang sama berubah menjadi Japao dan China dalam versi Brasil.

Beberapa perubahan mungkin saja bersifat adaptasi transliterasi, adaptasi morfologis, adaptasi budaya, atau substitusi. Yang menarik adalah bahwa nama yang ada dalam suatu cerita memiliki bentuk dan fungsi tertentu. Berbeda dengan kata benda yang lain, nama diri ternyata bersifat mono-referensial dan monofungsional. Ini berarti, nama yang digunakan memiliki referensi tunggal yang fungsinya untuk memberikan identitas pada si tokoh. Meskipun dalam dunia nyata nama seringkali tidak dianggap deskriptif, nama dapat memberikan gambaran tentang sosok pemiliknya, sifat yang melekat padanya (meskipun tidak selalu akurat), jenis kelamin, asal daerah, atau bahkan keyakinannya.
Kasus penerjemahan nama diri tersebut muncul pada saat peneliti mendampingi mahasiswa yang sedang melaksanakan praktikum penerjemahan di semester genap 2012/2013. Beberapa mahasiswa yang terlibat penerjemahan suatu buku yang berjudul American Indian Mythology menanyakan tentang penerjemahan nama diri dalam buku tersebut. Beberapa mahasiswa merasa bahwa ada beberapa nama yang bisa diterjemahkan secara harfiah ke dalam bahasa sasaran(bahasa Indonesia), dan ada beberapa nama yang lain yang menurut mereka tidak perlu diubah menjadi nama Indonesia. Hal ini memunculkan motivasi untuk mengungkap strategi atau cara mahasiswa menerjemahkan nama diri yang mereka jumpai. Untuk mengetahui strategi penerjemahannya, maka perlu dilakukan suatu penelitian penerjemahan yang berbasis pada proses penerjemahan (bukan produk penerjemahan).

Dalam buku American Indian Mythology terdapat banyak nama diri, yang meliputi nama tokoh, nama tempat, unit satuan waktu, dan lain sebagainya. Sebagai contoh, Blackfeet, the Young Moon, Anishinabe, Buffalo Husband, dan Winter Man. Sebenarnya cara yang paling mudah untuk mentransfer nama diri adalah dengan teknik copy, yaitu menyalin nama tersebut apa adanya dalam bahasa sasaran. Namun, cara tersebut tidak selalu efisien karena penerjemah tentu saja tidak boleh berasumsi bahwa pembaca akan semuanya bisa memahami arti dari nama tersebut. Yang perlu diingat adalah bahwa nama Indian Amerika sering kali merepresentasikan sifat bawaannya. Apabila diterjemahkan dengan teknik copybisa saja menimbulkan masalah. Sebaliknya, apabila nama tersebut diterjemahkan secara harfiah, masalah lain akan muncul terutama dalam hal keberterimaan. Hal inilah yang sering membingungkan beberapa penerjemah.

Dalam penelitian ini masalah dibatasi hanya pada nama diri yang bersifat personal yaitu names of persons atau nama tokoh dalam mitologi tersebut. Pembatasan ini berdasarkan pada sifat teks yang sudah spesifik tentang Amerika. Besar kemungkinan, atau sebaiknya, nama-nama tempat tidak perlu diadaptasi atau diubah. Nama orang atau tokoh mendapat perhatian lebih karena beberapa nama seperti 
the Young Moon diterjemahkan secara literal menjadi Bulan Muda. Hal ini bisa saja menimbulkan reaksi pemaknaan yang berbada karena makna konotasi yang dimilikinya dalam bahasa Indonesia.

Selebihnya, masalah juga dibatasi pada strategi yang digunakan oleh penerjemah dan alasan pengambilan keputusannya. Artinya, jika ada campur tangan pihak lain tentang hasil terjemahannya (misalnya editor atau penerbit) maka hal itu diluar jangkauan penelitian ini. Peneliti hanya menggali informasi dari hasil terjemahan dan penerjemahnya.Masalah dalam penelitian ini dapat dirumuskan sebagai berikut.

1. Bagaimanakah mahasiswa yang mengambil Konsentrasi Penerjemahan menerjemahkan nama diri dalam American Indian Mytho$\log y$ ?

2. Apakah alasanmahasiswa menggunakan strategi penerjemahan yang mereka pilih?

Penelitian ini diharapakan dapat memberikan kontribusi pada mahasiswa terutama tentang penelitian penerjemahan yang berbasis pada proses. Selama ini kebanyakan penelitian penerjemahan berbasis pada produk terjemahan, sehingga proses di penerjemahannya tidak dapat diketahui. Dalam penelitian yang berbasis pada proses penerjemahan, selain data diambil dari produk terjemahan, proses penerjemahan juga turut diamati sehingga diketahui motivasi atau alasan penerjemah menggunakan strategi tertentu.

\section{Penerjemahan}

Menerjemahkan secara umum merupakan suatu proses mengalihkan makna, ide atau pesan suatu teks dari satu bahasa ke bahasa lain. Ada sejumlah pertimbangan yang menyertai usaha pemindahan, ide atau pesan tersebut, terutama menyangkut keutuhannya dalam produk terjemahan. Penting juga untuk dipertimbangkan apakah informasi yang diterima oleh pembaca teks dalam bahasa sasaran setara dengan informasi yang diperoleh pembaca teks dalam bahasa sumber. Pertimbangan-pertimbangan ini akan tampak dalam berbagai definisi penerjemahan yang dikemukakan oleh para ahli.

Hatim dan Munday (2004: 6) mendefinisikan penerjemahan sebagai 'the process of transferring a written text from source language (SL) to target language (TL)'. Dalam definisi ini, keduanya telah menyebutkan secara eksplisit tentang pengalihan makna atau pesan.

Menurut Nida dan Taber (1982: 18), 'translating consists in reproducing in the receptor language the closest natural equivalent of the source language message, first in terms of meaning, and secondly in terms of style'. Definisi ini lebih lengkap karena secara tersurat menyatakan bahwa penerjemahan berkaitan dengan permasalahan bahasa, pesan dan kesepadanan. Mereka juga memberikan penekanan khusus pada makna (meaning) dan bentuk (style) sebagai aspek penting dalam penerjemahan. Seorang penerjemah pertamatama harus memberikan perhatian pada makna untuk disampaikan. Kemudian bentuk atau gaya bahasa sebagai elemen berikutnya. Makna harus disampaikan apa adanya, sedangkan bentuk atau gaya bisa berubah. Pada karya sastra tertentu, bantuk atau gaya juga perlu untuk diperhatikan dan dipertahankan, sehingga hasil terjemahan tidak mengurangi fungsi estetis karya tersebut.

Dari beberapa definisi tersebut ditemukan kesamaan bahwa penerjemahan merupakan upaya untuk mencari padanan makna (equivalents) antara teks sumber (TSu) dan teks sasaran (TSa) sehingga tercapai kesepadanan (equivalence) yang terdekat dan alami (natural). Machali (2007) dan Baker (1992) menggarisbawahi istilah 'padanan makna' karena dalam penerjemahan maknalah yang dialihkan dari bahasa sumber ke bahasa sasaran. Dalam hal ini, penerjemah sebagai pengalih pesan, berhadapan dengan teks sebagai satuan makna (unit of meaning) dalam bentuk jajaran kata dan kalimat. Dengan demikian, bahasa yang digunakan merupakan 'satuan makna' berbentuk wacana yang bisa saling dipahami oleh partisipan (misalnya penulis dan pembaca) yang terlibat dalam tindak komunikasi tersebut (Machali, 2007).

\section{Nama Diri (Proper Nouns)}

Nama diri yang dimaksud dalam penelitian ini ada proper nouns atau ada yang menyebut sebagai proper names. Dalam Cambridge Advance Learners' Dictionary disebutkan bahwa proper noun adalah "the name of a 
particular person, place or object that is spelt with a capital letter", yaitu nama orang, tempat atau objek yang selalu ditulis dengan huruf capital. Dalam Modern English Grammar disebutkan ada enam macam proper nouns, yaitu: personal nouns (termasuk di dalamnya adalah nama orang, nama tokoh dalam cerita), names of geographical units (nama tempat, nama gunung, nama sungai, dan lain-lain), names of nationalities and religions (nama suku, nama agama, nama kepercayaan, dan lain-lain), names of holidays (nama hari besar, hari raya, hari kemerdekaan, dan lain-lain), names of time units (nama hari, nama bulan, nama tahun, dan lainlain), dan words used for personification (nama yang dianggap personifikasi, seperti Liberty, The One, Freedom, dan lain-lain). Selain keenam itu disebut sebagai common nouns. Common Nouns tidak ditulis dengan huruf awal kapital, kecuali di awal kalimat.

\section{Strategi Penerjemahan}

Berbagai istilah yang berkaitan dengan teknik penerjemahan sering digunakan dalam kajian teori penerjemahan. Machali (2000) dan Newmark (1988), misalnya, menggunakan istilah metode dan prosedur yang keduanya merupakan rencana atau cara dalam melakukan penerjemahan. Dalam pengertian ini, metode berada pada tataran makro teks secara keseluruhan sedangkan prosedur berada pada ranah mikro teks, satuan-satuan kebahasaan seperti kalimat, klausa, frasa dan kata. Teknik, lebih lanjut, cenderung bersifat praktis atau merupakan langkah-langkah praktis dan pemecahan masalah penerjemah-an.

Suryawinata dan Haryanto (2003) berbeda pendapat dengan Machali. Mereka menyatakan bahwa prosedur penerjemahan, atau mereka menyebutnya sebagai strategi penerjemahan, dan teknik penerjemahan bukanlah hal yang berbeda. Keduanya adalah tuntunan teknis untuk menerjemahkan frasa atau kalimat (menurut peneliti, berurusan dengan masalah mikro teks). Menurut mereka, strategi penerjemahan dapat dibedakan menjadi dua, yaitu strategi struktural (berkaitan dengan penyesuaian struktur kalimat) dan strategi semantis (berkaitan dengan kejelasan makna kata atau kalimat).
Konsep-konsep di atas, jika ditelaah akan menunjukkan bahwa semuanya merupakan langkah-langkah yang dipakai oleh penerjemah untuk menyelesaikan permasalahan yang dihadapinya pada saat menerjemahkan suatu teks. Dengan kata lain, konsep-konsep tersebut terjadi dalam proses penerjemahan. Proses penerjemahan merupakan proses mental yang hanya dihadapi, dilakukan, dan dirasakan oleh penerjemah. Proses tersebut tidak tampak atau abstrak. Semuanya bermuara pada kompetensi penerjemah dan menjadi titik awal penerjemah dalam mengambil keputusan. Oleh sebab itu, proses penerjemahan tidak bisa diungkap hanya dengan melihat hasil terjemahan saja. Harus ada upaya berkomunikasi dengan penerjemah untuk menggali informasi tentang "pengalaman" penerjemah pada saat melakukan penerjemahan. Maka penelitian tentang proses penerjemahan akan lebih akurat ketika penerjemah masih dalam proses penerjamahan atau baru selesai melakukan aktivitas penerjemahan. Apabila penelitian tentang proses penerjemahan dilakukan pada periode yang berselang cukup lama (satu tahun, misalnya) dari berakhirnya proses penerjemahan, dikhawatirkan terjadi distorsi pada alasan penerjemah mengambil keputusan pada saat menerjemahkan. Mungkin juga penerjemah akan lupa detail aktivitasnya pada saat menerejemahkan.

Molina dan Albir (2002) membedakan kedua konsep tersebut dengan istilah strategi dan teknik penerjemahan dalam perspektif proses dan produk. Strategi merujuk pada prosedur yang disadari atau tidak disadari oleh penerjemah yang digunakan untuk memecahkan masalah pada saat melakukan proses penerjemahan. Sementara itu, teknik penerjemahan adalah hasil dari pilihan yang diputuskan oleh penerjemah pada level mikro yang bisa dilihat dengan membandingkan teks sumber dan teks sasaran. Lebih lanjut dijelaskan bahwa:

'Strategies open the way to finding a suitable solution for a translation unit. The solution will be materialized by using a particular technique. Therefore, strategies and techniques occupy different places in problem solving: strategies are part of the process, techniques affect the result. However, some mechanisms may 
function both as strategies and as techniques. For example, paraphrasing can be used to solve problems in the process (this can be a reformulation strategy) and it can be an amplification technique used in a translated text (a cultural item paraphrased to make it intelligible to TT readers). This does not mean that paraphrasing as a strategy will necessarily lead to using an amplification technique. The result may be a discursive creation, an equivalent established expression, an adaptation, etc.' (Molina dan Albir, 2002: 508)

Dengan demikian, perbedaan antara strategi dan teknik penerjemahan menjadi lebih jelas dan tidak rancu lagi. Dalam hal ini peneliti menggunakan istilah strategi penerjemahan karena peneliti memberikan penegasan bahwa penelitian ini adalah penelitian yang berbasis pada proses penerjemahan yang berujuan untuk menggali informasi dari penerjemah tentang cara dan alasan mereka.

Untuk mengklasifikasi strategi penerjemahan, peneliti menggunakan model klasifikasi strategi penerjemahan menurut Fernandez (2006) yang membaginya menjadi sepuluh jenis, yaitu rendetion, copy, transcription, substitution, recreation, deletion, addition, transposition, phonogical replacement, dan conventionality. Model klasifikasi ini dirasa sesuai karena model ini spesifik untuk mengklasifikasi nama diri. Klasifikasi ini digunakan oleh peneliti untuk mengidentifikasi strategi yang digunakan oleh mahasiswa dalam menerjemahkan nama diri.

\section{METODE PENELITIAN Rancangan Penelitian}

Penelitian ini menggunakan pendekatan kualitatif. Penelitian kualitatif yang digunakan dalam penelitian ini secara spesifik disebut sebagai penelitian yang deskriptif yang mendeskripsikan fenomena yang digali dari lapangan. Karena tujuan dari penelitian ini adalah mencermati suatu fenomena yang terjadi dalam satu konteks situasi yang spesifik, dapat dikatakan bahwa penelitian ini merupakan suatu studi kasus.

\section{Data dan Sumber Data}

Untuk mendapatkan informasi yang lengkap, ada dua sumber data yang digunakan, yaitu sumber data utama berupa buku American Indian Mythology karya Evelyn Wolfson yang diterbitkan oleh Enslow Publisher dan terjemahannya dalam bahasa Indonesia oleh mahasiswa Prodi Bahasa dan Sastra Inggris FBS UNY semester VI yang menempuh paket konsentrasi Penerjemahan. Sumber data kedua berupa informasi yang didapat dari penerjemah melalui wawancara untuk mengungkap alasan penggunaan strategi tertentu dalam penerjemahan nama diri.

Adapun data yang dianalisis berupa nama diri (proper nouns) yang terdapat dalam buku American Indian Mythology dan hasil terjemahannya dalam Bahasa Indonesia. Selain itu data hasil wawancara dengan penerjemah juga digunakan untuk mengungkap motivasi dan latar belakang penerjemah menggunakan strategi pilihannya. Secara umum wawancara dilakukan dengan menanyakan alasan penerjemah menerjamahkan suatu nama diri menjadi seperti apa yang muncul dalam versi Bahasa Indonesia. Setelah itu ditanyakan juga alat bantu apa yang digunakan oleh penerjemah, berapa kali ia mengganti hasil terjemahannya, dengan siapa ia berdiskusi, dan apakah keputusan yang diambil adalah keputusan yang tepat.

\section{Teknik Pengumpulan Data}

Untuk kelengkapan data, digunakan teknik pengumpulan data berupa analisis dokumen dan wawancara. Data utama diperoleh dari analisis dokumen terhadap buku American Indian Mythology. Seperti yang dikatakan Sutopo (2006), karena objek penelitian adalah teks, analisis dokumen menjadi sumber data pokok dalam penelitian ini.

Wawancara digunakan untuk mengumpulkan data agar diperoleh informasi yang dapat menjadi pertimbangan dalam melakukan analisis. Informasi atau data diperoleh dengan melakukan wawancara pada penerjemah. Tujuannya adalah untuk mengungkap motivasi yang melatarbelakangi mahasiswa menggunakan strategi tertentu dalam penerjemahan nama diri yang dijumpai dalam teks yang diterjemahkan. 


\section{HASIL DAN PEMBAHASAN}

Hasil penelitian menunjukkan bahwa mahasiswa menggunakan tujuh cara atau strategi dalam menerjemahkan nama diri. Ketujuh cara tersebut adalah copy, addition, deletion, rendition, transposition, conventionality, serta gabungan copy, addition dan rendition. Adapaun secara kuantitas, strategi yang digunakan memiliki sebaran dapat dilihat pada Tabel 1.

Dengan demikian, strategi copy menjadi strategi yang paling sering digunakan oleh mahasiswa diikiuti dengan strategi rendition. Dalam terminologi yang lain, copy juga dikenal dengan istilah pure borrowing. Strategi yang lain tidak banyak digunakan oleh mahasiswa, ditujukkan dengan jumlah penggunaan yang relatif sedikit. Bahkan beberapa strategi seperti transcription, recreation, dan phonological replacement tidak digunakan.

Pertimbangan makna menjadi latar belakang utama pemilihan strategi. Makna yang dimaksud dikaitkan dengan makna semiotik, semantik dan simbolik bunyi. Nama-nama yang mengandung makna semiotik, yaitu nama-nama yang lekat dengan budaya tertentu yang menunjukkan penanda, garis keturunan, berasosiasi dengan sejarah, menunjukkan gender, identitas agama, mitos dan lain sebagainya, cenderung diterjemahkan dengan strategi copy atau copy dengan penambahan atribut tertentu. Sedangkan nama-nama yang menunjukkan makna secara semantik, yaitu makna yang berpotensi me- miliki kualitas elemen naratif tertentu ataupun personifikasi, cenderung diterjemahkan dengan strategi rendition. Hal ini disebabkan namanama tersebut cenderung merupakan personifikasi dan memberikan gambaran pada pembaca tentang sosok karakter tertentu, sedangkan nama yang menunjukkan simbol bunyi tidak dijumpai dalam sumber data.

Pada kasus-kasus addition, penerjemah menambahkan atribut tertentu dalam terjemahan nama diri untuk memperjelas karakter suatu tokoh tertentu. Pada kasus deletion, atribut tertentu yang melekat pada tokoh tertentu dihilangkan karena sudah disebutkan dalam kalimat sebelumnya. Pada kasus substitution, penggantian suatu nama diri dilakukan karena alasan yang bersifat kontekstual. Sebagai contoh, crow diterjemahkan menjadi Raven dan Hopi Kachina diterjemahkan menjadi roh kachina (tidak menggunakan huruf kapital).

Berikut ini pembahasan tentang strategi penerjemahan nama diri dan alasan penggunaan strategi tersebut.

\section{Strategi Copy dan Makna Semiotik}

Strategi copy merupakan suatu cara yang digunakan oleh penerjemah untuk mengalihkan pesan dengan cara menyalin istilah / nama yang ada dalam bahasa sumber kedalam bahasa sasaran. Vinay dan Darbelnet menyebut strategi ini sebagai borrowing yang paling sederhana (pure borrowing). Penerjemah tidak merubah

Tabel 1. Strategi Penerjemahan Nama Diri

\begin{tabular}{|c|c|c|c|}
\hline No. & Strategi & Frekuensi & Prosentase (\%) \\
\hline 1 & Copy & 91 & 61,49 \\
\hline 2 & Rendition & 43 & 29,05 \\
\hline 3 & Addition & 5 & 3,38 \\
\hline 4 & Deletion & 4 & 2,71 \\
\hline 5 & Conventionality & 3 & 2,03 \\
\hline 6 & Transposition & 1 & 0,67 \\
\hline 7 & Gabungan copy, addition dan rendition & 1 & 0,67 \\
\hline Jumlah & & 148 & 100 \\
\hline
\end{tabular}

Tabel 2. Pertimbangan Makna dalam Penerjemahan Nama Diri

\begin{tabular}{clcc}
\hline No. & \multicolumn{1}{c}{ Makna yang Terkandung } & Frekuensi & Prosentase (\%) \\
\hline 1 & Makna Semiotik & 101 & 68,24 \\
2 & Makna Semantik & 46 & 31,08 \\
3 & Gabungan Makna Semiotik dan Semantik & 1 & 0,68 \\
\hline Jumlah & & 148 & 100 \\
\hline
\end{tabular}


atau mengganti unsur-unsur ejaan maupun mengganti unsur-unsur bunyinya.

Dalam data penelitian ini dijumpai banyak strategi ini. Secara kuantitatif jumlahnya mencapai 91 (61,49\%), yaitu frekuensi tertinggi penggunaan strategi penerjemahan nama diri. Sebagai contoh, nama Raven, Micmac, Lewis, Clark, FranzBoas, Mooney. Ho-e-ma-ha, Tihkuyi, Havasupai, Zeus, Kuhkw, Coolpujot dan lain-lain. Semuanya diterjemahkan persis sama dengan yang tertulis dalam bahasa sumbernya. Alasan penggunaan strategi ini adalah bahwa nama-nama tersebut diidentifikasi tidak memiliki makna secara semantik. Setidaknya hal ini yang ditangkap oleh penerjemah. Namanama ini tidak diubah karena memiliki makna semiotik dan terikat pada budaya bahasa sumber. Para penerjemah juga tidak melakukan borrowing jenis lain, yaitu naturalizedborrowing yang meminjam nama bahasa sumber dengan adaptasi penyesuaian ejaan maupun pelafalan dalam bahasa sasaran. Hal ini dilakukan untuk menjaga nuansa budaya bahasa sumber.

Secara ideologis, strategi ini cenderung berpihak pada bahasa sumber, atau dikenal dengan ideologi foreignization. Yang mendasari ideologi ini adalah bahwa penerjemahan yang 'betul', 'berterima', dan 'baik' adalah terjemahan yang sesuai dengan selera dan harapan pembaca sasaran yang menginginkan kehadiran budaya bahasa sumber atau menganggap kehadiran bahasa sumber memberikan manfaat bagi masyarakat (Hoed, 2006: 87). Meskipun teks telah berubah bahasa, suasana dan budaya bahasa sumber dipertahankan untuk dapat tetap hadir dalam teks bahasa sasaran. Nilai-nilai budaya dan nuansa bahasa sumber tetap dihadirkan dalam teks bahasa sasaran karena dapat memberikan pengetahuan tambahan kepada pembaca teks bahasa sasaran tentang budaya asing.

Hagfors (2003) termasuk salah satu tokoh yang mendukung ideologi ini, terutama penerjemahan teks untuk anak-anak. Ia menyatakan bahwa:

"Depending on the choice of global and local translation strategies, translated children's literature can be either a means of bridging cultural differences or of obscuring them. If culture-bound elements are foreignized the story can serve as a tool for learning about foreign cultures, times and customs and intrigue readers to find out more about them. In other words, foreignized children's stories are a way of drawing attention to cultural matters: to learn what is different and what is shared between the reader's culture and that in which the story is set."

Penerjemahan berperan signifikan dalam menjembatani perbedaan budaya antara budaya dalam teks bahasa sumber dengan pembaca teks bahasa sasaran. Anak-anak akan bisa lebih memahami dan mengerti budaya daerah lain atau negara lain. Melalui karya sastra terjemahan, anak-anak bisa mulai memahami permasalahan dan fenomena budaya dalam masyarakat sosial yang lain, memahami persamaan dan perbedaannya dengan budayanya sendiri. Jadi, pada saatnya nanti mereka tidak mengalami cultural shock yang hebat.

Pascua (2003) menyatakan bahwa penerjemahan memiliki peranan yang penting dalam pendidikan lintas budaya.

"As my main task as a translator is to let my readers know more about the foreign and the "other," I would naturally opt for "foreignization": keeping the exotic and the unknown in the translated text. Keeping intercultural education in mind when translating for children it is important to maintain the "cultural references" of the original text, and pay attention to the issues of acceptability and readability. The translated text should not maintain the "linguistic discourse" of the original language as we have to pay attention to the future readers, the children. They will not like a text with strange-sounding sentences and complex grammatical structures. Different treatment should be given to those cultural markers which introduce Spanish readers to new worlds. Readers will understand that it is a foreign text and should "feel" that they are reading a translation if not only for the exotic 
names, places, food, clothes, customs, etc. (see Pascua 2000 and 2001). Unlike the norm in Spain a few decades ago, which required translated texts to "sound" very Spanish, this way of translating emphasizes the different - something essential on translating multicultural literature."

Foreignization dalam penerjemahan menjadi suatu strategi mempertahankan dan menyampaikan referensi budaya teks bahasa sumber. Dengan demikian pembaca teks bahasa sasaran akan mengalami eksotisme teks asli dan pengalaman baru.

Lebih lanjut, meskipun penerjemah memilih ideologi foreignization, harus tetap dipahami bahwa penerjemah,dengan segenap pertimbangan yang diambilnya, hendaknya selalu mengedepankan dengan keberterimaan dan keterbacaan. Pembaca tidak akan senang atau nyaman jika membaca teks yang terasa janggal atau mendapati kalimat yang terlalu kompleks. Ideologi ini memiliki beberapa kelebihan dan kelemahan dapat dilihat pada Tabel 3.

Dalam penelitian ini tetap dijumpai beberapa nama yang mengandung makna semantik yang diterjemahkan dengan strategi copy ini. Sebagai contoh nama-nama seperti Dog Salmon, Magpie, Hawk, Beetle, Holly, Great Lakes, dan Old Oraibi. Nama-nama ini sebenarnya bisa diterjemahkan dengan strategi lain, yaitu rendetion. Beberapa penerjemah nama-nama tersebut teridentifikasi memang hampir selalu menggunakan strategi copy dengan alasan strategi ini digunakan untuk tetap menjaga nuansa budaya bahasa sumber, dan bisa dipastikan keakuratan maknanya.

\section{Strategi Rendition dan Makna Semantik}

Strategy Rendetion, atau juga disebut literal translation, seperti yang disampaikan oleh Fernandez (2006), digunakan ketika nama bersifat transparent atau secara semantik terpengaruh atau berada dalam bahasa yang baku, yaitu manakala nama dalam bahasa sumber terdapat dalam daftar leksikon bahasa tersebut sehingga memiliki padanan dalam bahasa sasaran. Sebagai contoh, nama "Cat" dalam bahasa Inggris diterjemahkan menjadi "Kucing" dalam bahasa Indonesia.

Para mahasiswa cukup sering menggunakan strategi ini. Ada 43 (29,05\%) nama diri yang diterjemahkan dengan menggunakan strategi rendetion. Berikut beberapa contoh data hasil terjemahan mahasiswa.

Kata Young Moon diterjemahkan menjadiSang Bulan Muda dan Bulan Muda, OldMoon diterjemahkan menjadi Sang Bulan Tua, Buffalo Husband diterjemahkan menjadi Suami Kerbau, Mountain Lion diterjemahkan menjadi Singa Gunung, Eagle-Spirit menjadi Roh Elang, Creator of the Game Animal menjadi Pencipta Hewan Buruan, dan Maker of Life menjadi Pemberi Kehidupan. Data ini didapat tidak hanya dari satu penerjemah saja, melainkan dari beberapa mahasiswa yang terlibat dalam penerjemahan buku American Indian Mythology.

Dari wawancara yang dilakukan terhadap penerjemah, strategi ini dipilih karena nama dalam bahasa sumber memiliki makna makna secara leksikal dalam bahasa Inggris dan juga memiliki padanan dalam bahasa sasaran, Bahasa Indonesia. Dengan kata lain, nama diri yang terdapat dalam bahasa sasaran memiliki makna secara semantik sehingga apabila menggunakan strategi lain dalam penerjemahannya, misalnya strategi copy, maka hasilnya tidak berterima. Selain memiliki makna secara semantik, nama-

Tabel 3. Kelebihan dan Kekurangan Ideologi Foreignization dalam Penerjemahan

\begin{tabular}{ll}
\hline \multicolumn{1}{c}{ Kelebihan } & \multicolumn{1}{c}{ Kekurangan } \\
\hline $\begin{array}{l}\text { Pembaca teks BSa memahami budaya teks } \\
\mathrm{BSu}\end{array}$ & $\begin{array}{l}\text { Kejelasan makna sulit ditangkap oleh } \\
\text { pembaca teks BSa }\end{array}$ \\
\hline $\begin{array}{l}\text { Kehadiran nuansa budaya teks BSu } \\
\text { dirasakan oleh pembaca teks BSa }\end{array}$ & Kealamiahan teks BSa berkurang \\
\hline $\begin{array}{l}\text { Memungkinkan adanya intercultural dan } \\
\text { multicultural learning }\end{array}$ & $\begin{array}{l}\text { Munculnya resistensi terhadap nilai-nilai } \\
\text { budaya teks BSu oleh pembaca teks BSa }\end{array}$ \\
\hline
\end{tabular}


nama dalam contoh di atas juga menyiratkan karakter, sifat atau wujud dari tokohnya.

\section{Strategi Lainnya karena Makna Semiotik dan Semantik}

Strategi lain yang digunakan oleh penerjemah adalah addition (5 data), deletion (4), conventionality (3), transposition (1), serta gabungan addition, copy dan rendition (1). Meskipun jumlahnya tidak banyak, temuantemuan ini tentu cukup menarik untuk dianalisis.

Strategi addition bersifat penambahan informasi terhadap nama asalnya. Seringkali strategi ini dilakukan untuk menghindari ketaksaan pada hasil terjemahannya. Beberapa hasil terjemahan mahasiswa yag mengunakan strategi ini adalah sebagai berikut. Raven diterjemahkan menjadi Raven, si burung gagak, Bluejay menjadi Burung Bluejay, Cedar menjadi Pohon Cedar, Januari menjadi Bulan Januari, dan May menjadi Bulan Mei. Kata atau frasa yang bergaris bawah adalah tambahan. Beberapa mahasiswa memberikan tambahan untuk memberikan penegasan terhadap sifat atau perwujudan dari nama yang dimaksudkan.

Strategi deletion menghilangkan nama atau bagian teretentu dari nama pada teks sumber. Unsur yang dihilangkan umumnya merupakan unsur yang tidak dianggap penting oleh penerjemah. Sebagai contoh, dalam data dijumpai nama Puget Sound diterjemahkan menjadi Puget, Tolowim-Woman menjadi Tolowim, Grandfather Buzzard menjadi Buzzard, dan BeaverGrandchildren tidak direalisasikan. Beberapa unsur yang dihilangkan dianggap sudah cukup jelas karena sudah disebutkan di dalam kalimat sebelumnya, sehingga tidak dirasa pen-ting untuk menambahkan unsur tersebut di dalam kalimat berikutnya.

Strategi conventionality digunakan oleh penerjemah untuk menerjemahkan nama-nama yang sudah ada padanannya secara umum. Dalam data dijumpai beberapa nama yang diterjemahkan dengan menggunakan strategi ini. Sebagai contoh, nama September, October dan Pine diterjemahkan menjadi September, Oktober dan Pinus. Dalam terminologi lain, conventinality disebut juga established equivalent.

Transposition merupakan strategi yang bertujuan untuk merubah jenis kata tanpa bermaksud untuk merubah makna. Misalnya merubah kata benda menjadi kata sifat atau sebaliknya. Dalam penelitian ini satu data dijumapai menggunakan strategi ini, yaitu nama Running Fast diterjemahkan menjadi Si Pelari Cepat. Kata Running adalah gerund, sementara kata Pelari adalah kata benda. Karena dalam bahasa sasaran, bahasa Indonesia, tidak memiliki gerund, maka yang paling dekat dengan gerund adalah kata benda karena memiliki fungsi yang serupa dalam kalimat.

Strategi terakhir adalah strategi gabungan antara addition, copy dan rendition. Contoh dari strategi ini adalah Glooscap the Teacher yang diterjemahkan menjadi Glooscap Sang Maha Guru. Hasil terjemahan menambahkan kata Maha untuk mempertegas makna. Glooscap menjadi Glosscap adalah copy, sedangkan Teacher menjadi Guru adalah rendition.

\section{PENUTUP}

Hasil penelitian menunjukkan bahwa strategi yang digunakan oleh penerjemah antara lain: copy (91 data), rendetion (43), addition (5), deletion (4), conventionality (3), transposition (1), serta gabungan copy, addition dan rendition (1). Copy menjadi strategi yang paling sering digunakan oleh mahasiswa diikiuti dengan strategi rendition. Strategi yang lain tidak banyak digunakan oleh mahasiswa, ditujukkan dengan jumlah penggunaan yang relatif sedikit. Pertimbangan makna menjadi latar belakang utama pemilihan strategi. Makna yang dimaksud dikaitkan dengan makna semantik, semiotik dan simbolik bunyi.Secara umum dapat disimpulkan bahwa kandungan makna yang terdapat di dalam nama diri menjadi faktor utama pemilihan strategi penerjemahan yang dipilih oleh penerjemah.

Strategi copy lebih banyak digunakan karena dalam teks bahasa sumber lebih banyak dijumpai nama diri yang mengandung makna semiotik. Strategi ini dianggap tepat karena nama diri yang mengandung makna semiotik tidak dijumpai padanannya dalam bahasa sasaran. Sementara itu, strategi rendetion menjadi pilihan kedua terbanyak. Hal ini terkait dengan dijumpainya berbagai nama diri yang mengandung makna semantik sehingga secara harfiah dapat dijumpai padanannya dalam bahasa sasaran. 
Oleh sebab itulah, para penerjemah memilih untuk menggunakan strategi rendetion.

Beberapa nama diri yang mengandung makna semiotik diterjemahkan dengan berbagai pilihan strategi seperti addition, deletion, dan transposition, sedangkan convetionality menjadi alternatif lain untuk menerjemahkan nama diri yang mengandung makna semantik. Kemunculannya yang minor terjadi karena faktor-faktor khusus terkait dengan konteks pemahaman penerjemah.

Strategi gabungan juga menjadi alternatif penerjemahan manakala nama diri yang ada mengandung gabungan makna semantik dan semiotik. Gabungan beberapa strategi dipilih untuk menyampaikan setiap detail makna yang ada dalam nama diri tersebut. Gabungan strategi yang digunakan adalah copy, rendetion, dan addition.

\section{DAFTAR PUSTAKA}

Baker, Mona (1992). In Other Words, A Coursebook on Translation. London: Routledge

Fernandez, Lincoln (2006). "Translation of Names in Children's Literature: Bringing the Young into Play". New Voices in Translation Studies 2. pp. 44-57.

Hatim, Basil dan Jeremy Munday (2004). Translation, An Advanced Resource Book. London: Routledge.

Hagfors, Irma. 2003. 'The Translation of Culture-Bound Elements into Finnish in the Post-War Period' dalam META, XLVIII, 1-2, 2003 halaman 125.
Hoed, Benny Hoedoro. 2006. Penerjemahan dan Kebudayaan. Jakarta. PT Dunia Pustaka Jaya.

Machali, Rochayah (2000). Pedoman Bagi Penerjemah.. Jakarta: Grasindo.

Machali, Rochayah (2007). Campur Tangan Penerjemah: 'mengkhianati' teks asli? Makalah dalam Seminar Nasional Penerjemahan. FBS UNY.

Molina, Lucia and Albir, Amparo Hurtado. 2002. 'Translation Techniques Revisited: A Dynamic and Functionalist Approach'. Dalam META: Journal des traducteurs/Meta: Translators'Journal. XLVII, No. 4 hal. 498-512.

Newmark, Peter (1988). A Textbook of Translation. Hertfordshire: Prentice Hall International.

Nida, Eugene A. and Charles Taber. 1982. The Theory and Practice of Translation. Leiden: E.J. Brill.

Nord, Christiane. (2003). Meta, XLVIII, 1-2, 2003. "Proper Names in Translations for Children: Alice in Wonderland as a Case in Point".

Pascua, Isabel. 2003. 'Translation and Intercultural Education'. Dalam META, XLVIII, 1-3, 2003, halaman 280.

Suryawinata, Zuchridin dan Sugeng Haryanto. 2003. Translation (Bahasan Teori dan Penuntun Praktis menerjemahkan). Yogyakarta: Kanisius.

Sutopo, H.B. 2006. Penelitian Kualitatif: Dasar Teori dan Terapannya dalam Penelitian. Surakarta: Universitas Sebelas Maret. 